\title{
NOTAS SOBRE AS REVOLTAS E AS REVOLUÇÕES DA EUROPA MODERNA*
}

\author{
Profa. Dra. Laura Mello e Souza \\ Depto. de História-FFLCH/USP
}

\begin{abstract}
RESUMO: Este artigo procura fazer um balanço geral da historiografia européia referente às revoltas e revoluções da Europa Moderna, enfatizando sua incidência no século XVII, e apontando para possibilidades de pesquisa que, fora do recorte meramente político, ofereçam alternativas analíticas.
\end{abstract}

\begin{abstract}
This article presents an overall balance of the European historiography concerning the revolts and revolutions in Modern Europe, emphasizing its incidence in the seventeenth century and pointing out the possibilities of research which, apart from the merely political context, offer analytical alternatives.
\end{abstract}

PALAVRAS-CHAVE: Revoltas, revoluções, crise, sociedade do Antigo Regime, Século XVII

KEYWORDS: revolts, revolutions, crisis, Ancient Regime society, scventeenth century

"As revoluçōes são quase tão dificeis de
reconstruir quanto de prever".

Forster e Greene

- Este é o texto da prova escrita do Concurso para a LivreDocência junto ao Departamento de História, na Disciplina de História Moderna, que realizci no final de agosto de 1993. A banca examinadora era composta dos Profs. Drs. Maria Manuela Ligeti Carneiro da Cunha (DA.FFLCH-USP), José Jobson de Andrade Arruda (DH-FFLCH-USP), Francisco Iglésias (DE-FCE-UFMG). Gilberto Cardoso Alves Velho (DA.PPGAS-MN/UFGJ) e Stuant B.Schwarz (HD-UM). Mantive o texto original, com un ou outro acréscimo bibliográfico, e umas poucas linhas acerca do texto de Giovanni Birago, que me chegou as matos dois anos depois, no final de 1995. Devo a referência a meu amigo Robert Rowland, a quem, mais uma vez, sou profundamente grata.
I. O debate sobre as convulsões políticas e sociais que, no bojo de uma crise econômica secular, abateram-se sobre a Europa no decorrer do século XVII, um dos mais significativos da historiografia européia dos anos 50 e 60 deste século. Para Christopher Hill, o estudo desses fenômenos seria mesmo "o teatro mais importante no qual se livrava a batalha pelo marxismo" (VILLARI, 1981). No que diz respeito ao enfoque econômico, a grande crise de crescimento evidenciada, segundo Ruggiero Romano, por volta de 1620 permitiria que Eric J. Hobsbawm questionasse os descaminhos da pujança material do século XVI, formulando pergunta bem ao gosto do marxismo de então: "por que a expansão dos séculos 
XV-XVI não conduziu diretamente à época da revolução industrial dos séculos XVIII-XIX? Quais os obstáculos à expansão capitalista?" (HOBSBAWM, 1971). No que diz respeito a abordagem mais voltada para o social e o político, Hugh-Trevor-Roper veria, na sucessāo setecentista de levantes e sediçōes, o coroamento da irracionalidade do Estado Renascentista, cxcessivamente pesado e dispendioso, cada vez mais distante do corpo social (ROPER, 1972). Roper, evidentemente, destoava das análises marxistas, gerando uma célebre discussão com - grupo "new-left" da Past and Present e scndo execrado entre os marxistas num âmbito tão ou mais internacional quanto o da crise que se analisava. Já no tocante ao recorte de cunho mais ideológico, ou melhor, no que tange ao estudo das idcologias, Gcorge Rudé c Robert Mandrou procuraram refletir sobre o caráter de tais levantes, valendo-se, no primeiro caso, das abordagens de G. Luckács c A. Gramsci e, no segundo, de uma apropriação livre e interessante das idéias de Lucien Goldmann (RUDÉ, 1981; MANDROU, 1965).

Pela amplitude dos enfoques e pela abundância dos estudos, nota-se que C. Hill estava ccrto, mas, também, que tal debate extrapolava o âmbito da historiografia marxista, provocando adesōes tam. bém à direita, como o referido Trevor-Roper $e$ ainda Roland Mousnier, o teórico francês da sociedade de ordens, o estudioso da Fronda e do Estado Absoluto sob os Bourbons. Além da já mencionada discussão sobre crescimento econômico e crise, o século XVIII, nos seus infortúnios, funcionava como laboratório para reflexōes sobre a naturcza das lutas sociais, sobre a historicidade da luta de classes, sobre a possibilidade de tais lutas ocorrerem em formações sociais em que os grupos integrantes ainda nāo haviam amadurecido a consciência de si etc. Mais recentementc, até estudos vistos como mais soft em termos de ideologia e mesmo de relevância historiográfica, como a análise da perseguiçāo às bruxas, têm se reportado à crise multifacetada do século XVII em busca de balizas cronológicas mais definidas e de explicaçōes mais convincentes (LEVACK, 1987). O próprio Roper, historiador polêmico, paradoxal, inquieto e brilhante como poucos, arrisca a relaçăo entre crise geral do século XVII e perseguição generalizada às bruxas no ocidente europeu (ROPER, 1988).

Scria impossível, no âmbito deste texto, esgotar as relaçōes possíveis suscitadas pela questão das revoltas e revoluçōes da Europa Moderna. Procurando apenas encaminhar alguns problemas e arriscar conclusōes, optei por uma discussão historiográfica restrita que, partindo da problemática da construção de modelos e de sistematizações gerais, passa, a seguir, para a busca de certos encaminhamentos específicos. Tais encaminhamentos redimensionam o problema que envolve revoluçăo enquanto conceito universal $\mathrm{e}$ absoluto $\mathrm{e}$ sugerem outras grades de leitura, influenciadas pela história antropológica e pela renovação da historiografia marxista.

II. Para melhor encaminhar o debate historiográfico, é nccessário demorar-se um pouco sobre os fatos históricos que caracterizam o período em estudo. Na perspectiva que vê a História como progres. so e que, desde a llustração, tem tido tanta importância nos estudos historiográficos, fornecendo inclusive os contornos da História como disciplina, ficava difícil entender por quê a cxplosão de riqueza que atinge a Europa do Renascimento não havia tido, como decorrência necessária, a revoluçāo industrial ou, pelo menos, o desenvolvimento econômico continuado $\mathrm{c}$ uma correspondente paz social $\mathrm{e}$ estabilidade política.

Com o arrefecimento dos surtos mortíferos de peste e de fome, verifica-se entre os séculos XV e XVI um considerável desenvolvimento demográfico c urbano; a cxpansão marítima propiciava o surgimento de portos extremamente dinâmicos - Cádiz, 
Sevilha, Antuérpia, Amsterdam, Lisboa ... -, o aquecimento das trocas comerciais favorecendo a acumulação de capital e o surgimento de riquezas consideráveis (BRAUDEL, 1979). Aliada, entretanto, a transformações agrárias que, em grande parte da Europa, diminuíram e fracionaram as posses camponesas de terra (os enclosures ingleses são o paradigma do processo), a pujança do capitalismo comercial fez-sc acompanhar de um custo social altíssimo. Junto com a riqueza moderna, capitalista, surge a pobreza também moderna c capitalista. O pobre deixa de ser o coitadinho de Cristo para se tornar, na expressão recorrente em tantos escritos da época, "o peso inútil da terra" (VVAA, 1979; GEREMECK, 1976). Muda, então, o sentimento com relação aos despossuídos; a iconografia fixou muito bem tal mutação de sensibilidade: lembremse os pobres odiosos, deformados, de olhar feroz e maldoso que povoam as telas flamengas (e holandesas) desde J. Bosch e P. Brucghel; lembre-se igualmente que, para muitos, a Holanda é a expressão mais feliz do capitalismo moderno (ZUMTHOR, 1959; SHAMA, 1988).

Homens que vagavam eram pobres por incúria e imprevidência. Mas o que dizer dos novos pobres, que trabalhavam e continuavam miscráveis? Em 1577, informava Jan van Houtte, sccretário Geral de Lcyden: "os trabalhadores pobres - melhor chamá-Jos escravos - depois de terem trabalhado toda a semana, vên-se obrigados a mendigar nos domingos para completarem seus salários." (LIS e SOLY, 1984, p. 88). $\mathrm{Na}$ Inglaterra, no momento $\mathrm{cm}$ que se abria a crisc secular, em 1618, Robcrt Reyce escreve que, nas partes de Suffolk em que "vivem ou vivcram os tecelōes, nclas se encontra o maior número de pobres" (idem). Dos trabalhadores c cothars, Francis Bacon dizia que eram "but housc beggars". No ocaso do século XVI, Castcla via-se às voltas com a subalimentação crônica; $50 \%$ da população rural não tinla terras, $65 \%$ vivia no limite da subsistência (LIS c SOLY, 1984, p.
94). Aliás, o sćculo de ouro espanhol é também o século dos pícaros e da moderna idéia de pobreza; em 1525, o judeu espanhol Juan Luís Vives publicava a De Subvencione pauperum. Por toda a Europa portanto, abria-sc o abismo entre pobres e ricos, acentuavase a distinção entrc capital e trabalho. "Uma pessoa possui o dinheiro, e outra faz o trabalho", dizia-se então (LIS e SOLI, 1984, p. 94).

No âmbito das classes proprictárias, a burguesia ia adquirindo terras e títulos de nobreza, traindo sua "vocação", na bela formulação de F. Braudel. Ridicularizando os "parvenus" como M. Jourdain, a paradigmática personagem de $O$ Burguês Fidalgo de Molière, os pobres de velha linhagem não desprezavam, entretanto, a riqueza fertilizadora que fluía destes membros do terceiro estado. Como disse muito bem Mme. de Sévigné, tais ingressos eram o esterco neccssário para revitalizar os seculares troncos nobres.

Uma sociedade polarizada em que o tom ainda era dado pela nobreza, lembrando a formulação clássica de Hans Freyer acerca da sociedade de estados (IANNI, p. 168). Mas uma sociedade em que também as classes proprietárias se viam sob impasses vários: dominante, na França, a nobreza de sangue tinha que se haver com a "toga"; rarefcita sob o impacto da Guerra das Duas Rosas, na Inglaterra, a velha nobreza via seus privilégios serem devorados pela "gentry"; acossada pela pujança dos súditos das Províncias Unidas, na Espanha, as famílias dos "grandes" castelhanos se lançam na Gucrra, deixando para trás os doze anos de trégua c arrastando, conforme a bela análise de Trevor Roper, a Europa loda para a sua primeira Conflagração Geral (ROPER, 1985).

Por loda a parte, como que tentando orquestrar a crisc cconômica, a misćria social, o fosso entre ricos c pobres, os desentendimentos entre várias gamas de nobres e burgueses, cresce o Estado Absolu10. Por toda a parte, em diferentes gradaçōes, o Rei 
deixa de convocar suas assembléias - Cortes em Portugal e na Espanha, Parlamento na Inglaterra, Estados Gerais na França - solapando as bases originárias sobre que se assentara a sociedade de estados. Dá as análises historiográficas falarem de crise geral: da economia, da política, da sociedade. $O$ indicador da crise, no plano econômico, $E$, para muitos, o fim do crescimento econômico frenético que caracterizara o século XVI; no plano político e social, a sucessão de revoltas, que atingem dimensão inaudita entre 1640 e 1660: na Inglaterra, o ápice da Revoluçāo de Cronwell, entre 1648 c 1653; na França, o da Fronda, entre 1648 e 1653; na Catalunha, a sedição separatista, auxiliada pelo governo francês entre 1640 e 1652; em Portugal, a guerra da Restauração, entre 1640 e 1648; em Nápoles, a revolta de Masaniello, nos anos de 1647.48; na Holanda, a tentativa de golpe de estado de Guilherme II; na Ucrânia, a insurrciçāo de 1650; na Suíça, a guerra camponesa de 1653; na Rússia, a rebcliño de Stenka Razin cm 1672.

III. Os autores que defendem a idéia de que ocorrera na Europa de entāo uma "revolução universal" invocam o exemplo de contemporâneos às sediçõcs, para quem sua generalidade era evidente. $R$. Mousnier lembra a Histoire des troubles de la Grande Brefagne. dc Robert Mentet de Saimonet, publicada em Paris em 1649 o que vê, no século XVII, "um século difícil, um século de ferro": "Toujours cst-il famcux pour lcs grandes et étranges révolutions qui y sont arrivēs. (...) Les révolts y ont ćte fréquentes tout dans l'Orient que dans l'Occident" (MOUSNIER, 1967, p. 9). Curiosíssimo é o caso de Giovanni Battista Birago, que en 1653 publicou em Veneza, no âmbito das Historie memorabili de Alessandro Zilioli, uma parte sobre as Sollevationi di stato de' nostri tempi, ncla incluindo, ao Iado da Catalunha. da Inglaterra, da França, de Portugal, da Sicília e de Nápoles, o Nordeste da América Portuguesa, que lutava con- tra os holandeses (BIRAGO, 1653, pp.160-171). Tal inclusāo é, no mínimo, intrigante: indício, talvez, de que, na época, o mundo ultramarino ainda era visto como parte integrante dos impérios curopeus, nāo se estabelecendo diferenças substantivas entrc a Sicília e Pernambuco. O primeiro grande impacto sobre o sistema europeu dos impérios modernos viria com o término da Guerra dos Trinta Anos (TILLY, 1996, p. 215 e segs), e só $\mathrm{em}$ meados do século seguinte - no plano das idéias, com Raynal; no plano das açōes práticas, com a revolta dos colonos ingleses da América do Nortc - é que se tornaria nf́tido, para a consciência curopéia, o real significado da sublevação em colônias.

Mas voltcmos à historiografia de nosso século; o pioneiro do enfoque das revoltas da Época Moderna como sendo "universais" foi Roger Bigelow Merriman cm Six contemporaneous revolutions, publicado $\mathrm{cm}$ 1938. Tal obra fe $z$ escola, $\mathrm{c}$ seus ecos podem ser encontrados no já mencionado artigo de Trevor-Roper e ainda em trabalhos como o de Perez Zagorin, Rebels and Rulers - 1500-1660, e a coletânea organizada por Robert Forster $\mathrm{c}$ Jack P. Greene Revoluçōes e Rebeliōes na Europa Moderna. Nestes dois estudos, entretanto, há a ultrapassagem do cnfoque universalista $\mathrm{c}$ a preocupação $\mathrm{em}$ criar lipologias. Mousnier fica um pouco a margem: adotando a perspectiva universalista, cstabelecc comparaçōes entre levantes no Ocidentc e no Oriente procurando encontrar, neles, antes um nexo comum do que tipologias específicas.

Tome-se o caso de Zagorin. Comparando c criando tipologias, o autor procura compreender o caráter do fenômeno revolucionário, observando talvez com justeza que, para os contcmporâneos, revolução c rebelião são sinônimos, o conceito de revolução tendo migrado do contex to cosmológico - onde descrevia rotações de corpos celestes - para o social: "Quando se transplantou a atos humanos, a palavra continuou a recordar a idéia de circularidade e 
se referia ao ciclo de mudanças nos estados com sua concomitante agitação. Ainda não se via em revolução a associação com inovação deliberada c consciente, ou com progresso. Até o século XVII, não se usou revolução $\mathrm{em}$ sentido político. A primeira rebelião na história européia que foi considerada pelos contemporâneos como revolução foi a inglesa de 1688; mesmo assim, concebiam-na em termos cíclicos como uma restauraçāo da ordem legal, que o monarca deposto, Jaime II, tinha violado tiranicamente" (ZAGORIN, 1985, p.37).

Procurando tipologias e invocando a "Consciência cíclica" de revolução dos homens do século XVII, Zaforin abraça, na verdade, posiçāo conservadora no tocante às revoluçōes: clas não sāo capazes de ultrapassar o caráter da sociedade de que fazem parte, inscrevendo-se nos limites de sua época (ZAGORIN, 1985, p. 42). Valorizando o âmbito geográfico em que ocorrem, cstendendo para o século XV o arco da periodização, endossando tipologia mista para elas - rcbcliōes agrárias, como a gucrra camponesa da Alemanha ou a rebeliāo de Ketl na Inglaterra dos Tudor; rebeliōes urbanas, como as francesas e espanholas, na verdade tão distintas umas das outras; rebeliões provinciais, como a dos $\mathrm{Nu}$ Pied na França, a Restauração Portuguesa, as revoltas de Aragão, da Irlanda, da Escócia; guerras civis, como a da França sob os últimos Valois, a dos Países Baixos contra a Espanha, a Fronda, a revoluçāo inglesa de 1640 - Zagorin csvazia tais fenômenos do scu conteúdo virulento $\mathrm{c}$, homogeneizando-os, no limite, os neutraliza.

A coletânea de Forster $\mathrm{c}$ Greene, rica em questōes e contendo alguns ensaios clássicos, como o de Mousnier sobre a Fronda c o de Laurence Stone sobre a Revolução Inglesa, acaba sendo engolfada pela mesma vertigem universalista-tipológica. Da convulsão seiscentista, destaca as grandes revoluçōes nacionais (a inglesa c a holandesa, que surge no século $\mathrm{XVI}$ ); as revoltas nacionais com potencial para transformar-se ém revolução (como a catalã e a francesa); a rebelião regional em grande escala com potencial limitado para se converter em revolução (como a de Pugochov), o golpe de estado secessionista (o português) e as jacqueries urbanas (na Sicília e cm Nápoles). Mais uma vez, a tipologia não consegue captar as especificidades, e o caráter universalista-neutralizador leva a melhor. Se os ótimos estudos de Mousnier e Stone já mencionados apontam a riqueza das situações particulares em História, a introdução dos autores insiste na camisa-deforça da generalização, e acaba enveredando pela seara do indistinto. Os movimentos do século XVII são assim apresentados como "antecedentes" das "grandes revoluções do final do século XVIII" (ZAGORIN, 1985, p. 12).

Por fim, entre os adeptos da idéia de "revolução univcrsal", Mousnier busca, para além de suas revoltas, da França à China, a persistência dos "furores camponeses", de um caráter informe e assistemático, próprio ao momento histórico em estudo e, em última instância, incapaz e/ou insuficiente de subverter a ordem, instaurando uma outra, nova: impotente, portanto, para realizar a revolução (MOUSNIER, 1967). A todas essas formulações cabe aplicar a crítica aguda que A. Lublinskaya fez sobre o trabalho de T. Roper: criam multidões de revoluçōes para, em seguida, destrui-las; homogencizam fenomenos radicalmente distintos, tendo como base comum tāo-somente a simultaneidade (LUBLINSKAYA, 1983).

IV. Sem se aterem ao caráter "universal" das revoltas, ou, pelo menos, sem procurar crigi-lo em catcgoria explicativa, há um outro grupo de historiadores que ainda persegue modelos e sistematizações, mesmo que de forma implícita. Tais sistematizaçōes não se pautam, portanto, na simultaneidade das revoltas, e sim no seu caráter: em outras palavras, procuram detectar a existência ou não da 
luta de classes ou da revolução burguesa nos fenômenos em estudo.

Para a discussão sobre a existência de luta de classes nas revoltas do século XVII, o caso francês foi especialmente importante, sobre ele tendo se debruçado alguns dos principais estudiosos do assunto; houve inclusive polêmicas, simbolizadas na oposição entre R. Mousnier e B. Porshnev. Se Mousnier não vê luta de classes, destacando o caráter espontaneísta e assistemático dos levantes, Porschnev matiza a questão detectando, nos levantes, o choque entre duas "frentes de classes": de um lado, a massa dos artesãos e dos camponcses, opositores do fisco e do feudalismo ao mesmo tempo; do outro, a burguesia e a nobreza, defensoras da preservaçāo da ordem feudal-absolutista. No limite, tal luta entre frentes de classes seria uma forma, seiscentista e moderna, da luta de classes (MOUSNIER, 1967; PORCHNEV, 1972).

A. Lublinskaya apresenta pontos de aproximaçīo com Porschnev ao ver nas convulsōes seiscentistas lutas de classes sem serem, entretanto, forma supcrior de luta de classes. No contexto francês, vê a nobreza e o campesinato como classes dotalas de consciência, c complementares, enquanto considera a burguesia como classe $\mathrm{cm}$ nível local, mas nāo nacional. A luta movida foi revolucionária na medida $\mathrm{cm}$ que se dirigia contra diferentes formas de exploração; para os camponeses, passar da luta contra os senhores feudais, típica do século XIV, para a luta contra o Estado feudal, própria ao século XVII, correspondeu a um amadurecimento ideológico. Năo havendo, portanto, "forma superior de luta de classes", ocorreu uma outra forma, tāo consciente $\mathrm{e}$ moderna quanto aquela, e assentada sobre contradiçōes das classes - mesmo que estas não se cxpressassem tão claramente quanto viriam a fazê-lo em 1789 .

Cabe por fim lembrar o estudo sugestivo de Mandrou, acima citado, que caracteriza a França do século XVII como "cspécic de vulcão de múltiplas crateras" (MANDROU, 1965,p.26) em que os trágicos conflitos sociais se mostram, na maior parte das vezes, inconsistentes, imersos no "patético cotidiano". Considerando que a conḍição de existência da luta de classes é a consciência de classe (o ser coletivo), Mandrou frisa que esta implica, por um lado, na solidariedade entrc os diferentes membros da classe $e$, por outro, na hostilidade ante outros grupos. Vê a nobreza como consciente do scu papel dominante; a burgucsia como "esquartejada" e os movimentos populares como oscilando entre a própria força revolucionária e a própria cegueira. A situaçāo francesa, paradoxal, se caracterizaria, assim, por classes superiores capazes de promover a transformaçāo política mas incapazes de imporem suas concepções de forma cficiente; por classes populares que, representando considerível massa de manobra, scmpre prestes a entrar em luta, nāo tinham projeto político c, em última instância, nāo tinham consciência de classe.

Para Mandrou, portanto, as sublevações francesas não tcriam sido luta de classes, apesar de terem aparência de luta de classes, sobretudo na violência demonstrada. Por outro lado, cram virtuais as suas aspirações de transformaçāo. "Uma classe que virtualmente descja fazer a revoluçĩo, mas que não tem consciência de que pode fazê-la, nāo ć uma classe revolucionária" (MANDROU, 1965, p. 78).

V. Cabe, por fim, apresentar os autores que, debruçando-se sobre as revoltas do século XVII, procuram se abster de tipologias ou modelos, buscando antes a sua cspecificidade. Nesta perspectiva, nāo faz sentido questionar o seu caráter de luta de classes, ou a sua força revolucionaria $\mathrm{com}$ base nos modelos criados a partir dos eventos de 1789 c 1848. Para eles, considerar a Revolução Francesa como modelo de revolução c, a partir dela, examinar fenômenos anteriorcs seria realizar a famosa "prcvisão do passado", o que distorceria o enfoque histórico no 
que tem de rico e particular. Há assim uma relativização do enfoque marxista no sentido em que este vincula, inextrincavelmente, revoluçāo com luta de classes, vendo a revolução francesa como o exem. plo supremo de tal relação.

A posição alternativa de Thompson é hoje célebre; sem sair do marxismo, vê as convulsões do mundo pré-industrial como "luta de classes sem classes". A consciência de classe $c$, portanto, a realização da própria classe seria decorrência do processo de luta; "as classes não cxistem como entidades separadas, que olham em volta, encontram uma classe inimiga e logo começam a lutar. Pelo contrário, as pessoas se encontram numa sociedade estruturada em modos determinados (crucialmente, porém não exclusivamente em relações de produção), experimentam a exploração (com a necessidade de se manterem sobre os explorados), identificam pontos de interesse antagônicos, começam a lutar por cstas questões e no processo de luta se descobrem enquanto classe, e chegam a conhecer este descobrimento como consciência de classe" (THOMPSON, 1981, p. 359).

Numa situação como a da Inglaterra setecentista - campo de estudo preferencial para Thompson - é necessário captar as resistências simbólicas oferecidas pelos grupos sociais, pois as classes têm de scr possíveis no conhecimento antes que encontrem expressão institucional. No contexto da cultura popular, tradicionalismo e rebeldia coexistem: podese ser rebelde $\mathrm{cm}$ defesa do costume, $\mathrm{e}$ invocando preceitos morais. Assim, o povo se revolta de forma violenta clamando pelo preço justo do pão: é o que Thompson, $\mathrm{cm}$ outro artigo fundamental, "A economia moral das classes populares inglesas no século XVIII" chama de "economia moral" das classes populares (THOMPSON, 1981, pp.57-136).

Rosario Villari e A. Lublinskaya, por vias diferentes, contribuem também para uma melhor compreensão dos levantes seiscentistas na medida $\mathrm{em}$ que destacam sua especificidade. Em "Revueltas y consciencia revolucionaria en el siglo XVII", o historiador italiano mostra que, mesmo se meramente anti-fiscal e espontânea, a revolta seiscentista é um momento revelador de ampla crise nas relaçōes sociais. Mais ainda: que, naquela época, o anti-fiscalismo é plèno de significado político: é anti-feudal; vincula-se a um discurso mais amplo sobre a hierarquia das ordens, o sistema de poder, as relações entre a ação do governo $\mathrm{c}$ o desenvolvimento da economia; vincula-se, por fim, a discursos sobre a revolução da ordem política e social que, apesar de fragmentários e interrompidos, vinham se constituindo ná época. Finalizando, Villari lembra que o século XVII foi mais importante que o XVI na formulação de discursos políticos. Em outras palavras, é importante atentar para a relação existente entre o alto índice de sublevações e o fato de, concomitantemente, estar sendo gestada a moderna idéia de revolução como subversão da ordem. Tal idéia, por sua vez, não se constituía apenas num lugar específico na Inglaterra, como se quis durante muito tempo -, pipocando aqui e ali, das Províncias Unidas insurgentes à França dos huguenotes (VILLARI, 1981).

Lublinskaya, por sua vez, fornece nova chave de compreensão aos levantes através de vias oblíquas. Ao contestar a idéia de Hobsbawn de que o século XVII sofrera uma crise econômica geral, a historiadora russa o acusa de se pautar no modelo de desenvolvimento industrial para, por meio dele, ler outras formas de desenvolvimento econômico. Ora, se o ritmo industrial é rápido, o ritmo e o desenvolvimento manufatureiros, próprios à Europa do século XVII - e Lublinskaya exemplifica quase sempre com o caso francês - é lento. Assim, cabe questionar se houve crise de crescimento, ou, pelo menos, se é pertinente a pergunta de Hobsbawm mencionada no início deste texto.

O desenvolvimento econômico do século XVIII inglês nāo valc para o exame da situação européia setecentista, e para a proclamação apressada de uma 
crise geral. Os modelos de revoluçăo e de luta de classes próprios ao século XVIII - leia-se à revolução francesa - nāo servem para examinar os conflitos do século XVII nem esvazia seu conteúdo revolucionário. A própria idéia de revolução ganha forças naquele contexto, como observa Villari. Os comentários de Thompson para os conflitos ingleses do século XVIII valem também para os levanies curopeus do século XVII: vê-los apenas como espontâneos c espasmódicos não corresponderia ao endosso de visão condicionada pela economia política, que reduz as trocas humanas a trocas salariais?

Por fim, sem querer alongar demais a lista dos autores aqui examinados, há que atentar para enfoques que, sem se debruçarem cspecificamente sobre as revoltas e revoluçōes do Seiscentos, podem, contudo, ajudar a melhor comprecndê-los. Lembrem-se os ensaios de Robert Darnton sobre $O$ grande massacre de gatos $\mathrm{e}$ o de Natalie Z. Davis sobre Os atos da violência e As razóes do desgoverno (DARNTON, 1986; DAVIS, 1990). Perscrutando as relaçōes entre a sociedade moderna (do Quinhentos e do Setecentos) e a violência, tais estudos mostram o scu caráter ritual e simbólico, por um lado profundamente diferente do que vemos hoje, por outro, tão fundamentais na constituição do moderno conceito de revolução. Se a violência passou a ser constitutiva da ruptura revolucionária - para invocar um s6 exemplo, tenha-se em mentc o terror revolucionário de 1793 -, ela já vinha sendo expressa, simbólica ou efetivamente, pelas práticas sociais desde o sćculo XVI. Havia cálculo e ordem nos ritos da violência, mostra Natalie Davis - sugerindo que talvez houves.

\section{Bibliografia:}

BJRAGO. G.B. Delle sollevabinni di stam accadute ne' mosmi rempi. Veneza. Presso il Turrini. 1653. se mais cálculo e ordem nos levantes anti-fiscais e nas revoltas "cspontaneístas" do século XVII do que poderia supor Roland Mousnier.

Olhar para o simbólico ccrtamente ajudará a compreender a natureza dos levantes do século XVII europeu. Ainda há poucas certezas sobre o assunto, c por isso termino este texto com algumas interrogaçōes. Talvez o grande esforço da revoluçăo setecentista tenha sido subtrair a violência do âmbito do cotidiano, inscrevendo-o no âmbito da exceção. Talvez o que tenha calado fundo na mentalidade seiscentista - daí os contemporâncos estarcm atentos a "revoluçĩo universal" de que falava Robert Mentet de Salmonct em 1649 - tenha sido justamente esse caráter cotidiano c gencralizado da violência. Violência que permeava as diversas instâncias da vida, da política ao imaginário, fundindo-as. "Rebellion is as the sin of witchcraft", dizia-se na Inglaterra seiscentista (CLARK, 1980). No final do século XVI, às vésperas da derrocada espanhola de 1588 quando a Invencível Armada de Filipe II seria sintomalicamente destruída por uma tempestade -, Lucrécia de Lcon tinha sonhos em que imagens terríveis e violentas represcntavam o fim da grande Espanha do Século de Ouro. Para R. Kagan, autor de um bclo livro sobre Lucrécia, scus sonhos expressavam a consciência social e política da Espanha do século XVI, sendo indicadores do imaginário da época. Mais ainda: através de imagens, durante o sono, Lucrécia vivia e previa a crise da Espanha. A Inquisição a levou a sério: foi presa e processada (KAGAN, 1990). Indício bastante forte da força do simbólico na sociedade de entāo.
BRAUDEL, F. Civilisution matérielle, économie ef capisalisme. Paris, Albin Miche!, 1979. 
CLARK, Stuart. "Inversion, misrule and the meaning of witcheraft". Past \& Present. 87, maio 1980, pp. 98-127.

DARNTON, R. $O$ grande massacre de gatos e outros episódios da história cullural francesa. Rio de Janeiro, Graal, 1986.

DAVIS, Natalie Z. Culturas do povo. Rio de Janeiro, Paz e Terra, 1990.

FORSTER, R. \& GREENE, Jack P. Greene, Revoluciones y rebeliones de la Europa Moderna. Madrid, Alianza, 1972.

GEREMECK, Bronislaw. Les marginatux parisiens aux XIVe et XVe siècles. Paris, Flammarion, 1976.

HOBSBAWN, E. J. "La crisis general de la economia europea en el siglo XVIII". in En torno a las origenes de la revolucioin industrial. Buenos Aires, Siglo XXI, 1971, pp. 7-70.

IANNI, O. (org.), Teorias de estratificaçao social, São Paulo, Cia. Editora Nacional, 1972.

KAGAN, R. Lucrecia's dreams - politics and prophecy in sixteenth-century Spain. Berkeley, University of California Press, 1990.

LEVACK, Brian P. The witch-hunt in early modern Europe. London and New York, Longman, 1987 ( traduçáo brasilejra: A caca às bruxus na Europa Moderna. Rio de Janeiro. Editora Campus, 1988).

LIS, C. e SOLY, H. Pobreza y capisalismo en la Europa preindustrial (1350-1850). Madrid, AKAl, 1984.

LUBLINSKAYA, A. D. La crisis del siglo XVIl y la sociedad del absolutismo. Barcelona, Crítica, 1983.

MANDROU, R. Classes et Luttes de Classes en France au début du XVIlle siès:le. Florença. G. D'Anne, 1965.

MERRIMAN, R. B.Six comtemporanerous rewolutions. Oxford, 1938.
MOUSNIER, R. Fureurs paysannes. Paris, Calmon-Lévy, 1967. PORCHNEV, B. Les soulevements populaires en France au XVIle siecle. Paris, Flammarion, 1972.

ROPER, Hugh Trevor. "A crise geral do século XVIII" in Religião, reforma e iransformaçán social. Lisboa, M. Fontes, 1972, pp. 43-72.

The European wirch-craze of the sixteenth and seventeenth centuries. Londres, Penguin Books, 1988.

"The outbreak of the Thinty-Years war" in Renaissance Essayss. s.l., Fontana Press, 1985.

RUDE. G. cap. "Ideologia e consciencia de clase" in Revuelta popular y consciencia de classe. Barcelona, Crítica, 1981, pp. 13-49.

SHAMA. S. - The embarassment of riches - an interpretation of Dutch culture in the golden age, s.l.. Fontana, 1988.

TILLY, Charles. Capital, conerçâo e cidades européias. São Paulo, EDUSP, 1996.

THOMPSON, E. P. Società patrizia, culsura plebea. Turim, Einaudi, 1982.

Cussoms in common - studies in traditional popular cullure. Nova York. The New Press, 1993.

VVAA. Les maryinaux et les exclus dans l'histoire. Paris, Éditions 1018, 1979.

VILLARI, R. Rebeldes y reformadores del siglo XVI al XVIII. Barcelona, Serbal, 1981.

ZAGORIN, Perez. Revueltas y revoluciones en la Edad Moderna. Madrid, Catedra, 1985.

ZUMTHOR, Paul. La vie quotidienne en Hollande au temps de Rembrandt. Paris, Hachette, 1959.

Endereço da Autora: Departamento de História-FFLCH/USP • Avenida Professor Lineu Prestes, 338 - CEP 05508-900 • Cidade Unjversitária • Sāo Paulo • Brasil • FAX: 55 (0I1) 818-3150 